\title{
The Frequency and Significance of Portopulmonary Venous Anastomosis (PPVA): A Case Report and Literature Review
}

\author{
Muhannad Al Hanayneh, Deborah Majchel-Koss, Eric Walser, and Richard W Goodgame* \\ Division of Gastroenterology and Hepatology, Department of Internal Medicine, University of Texas Medical Branch, USA
}

Received: October 15, 2014; Accepted: December 04, 2014; Published: December 15, 2014

*Corresponding author: Richard W. Goodgame, Division of Gastroenterology and Hepatology, Department of Internal Medicine, University of Texas Medical Branch, USA, Tel: 409-772-2653; Fax: 409-772-3394; E-mail: rwgoodga@utmb.edu

\begin{abstract}
A Portopulmonary Venous Anastomosis (PPVA) is a direct vascular connection between the portal venous system and the pulmonary veins, close to the left atrium. We describe a patient with advanced cirrhosis and moderately severe Hepatopulmonary Syndrome (HPS) in whom (PPVA) was demonstrated by a high resolution computed tomographic scan. In order to reduce the symptoms of hypoxia in our patient, we sequentially performed Transjugular Intrahepatic Portosystemic Shunt (TIPS) followed by a catheter based obliteration of the PPVA. The case raised three questions which were addressed through an extensive literature review.
\end{abstract}

Among patients with advanced cirrhosis, what is the frequency of PPVA? Our literature review suggests that the frequency of finding a PPVA in patients with portal hypertension depends on the imaging technique used. Transhepatic or transvenous portal venography may demonstrate PPVA in about $20 \%$ of patients with cirrhosis and varices. Limited published experience with contrast enhanced (bubble) echocardiography suggests that PPVA may be present in about $30 \%$ of such patients. An increasing number of case reports of PPVA have been published in recent years. This observation indicates that routine use of High Resolution Computed Tomography (HRCT) and magnetic resonance imaging is able to identify PPVA in cirrhotic patients. The visualization of PPVA with HRCT depends on the timing of the contrast injection and the expertise of the viewer.

Among cirrhotic patients with PPVA, what is the clinical significance of the PPVA? There are multiple causes of clinically significant hypoxia in patients with cirrhosis. A PPVA is a right to left shunt that, theoretically, could be associated with clinically significant systemic arterial hypoxemia or emboli. There is not definitive evidence in the published literature that PPVA alone causes clinically significant hypoxia in cirrhotic patients. PPVA is, however, a documented important risk factor for systemic emboli when needle or catheter techniques are used to treat or prevent bleeding from gastroesophageal varices.

What is the evidence that the obliteration of a documented PPVA will improve oxygenation in a cirrhotic patient with hypoxemia? Modern imaging methods may demonstrate a PPVA when patients with cirrhosis are investigated because of hypoxia. Previous authors have argued that the right to left shunting of blood in a PPVA does not have enough flow to significantly lower arterial oxygen concentration. Our report documents that the obliteration of a PPVA can be accomplished. However, our patient's oxygenation did not improve with obliteration of the PPVA. We do not believe that PPVA causes hypoxia. But knowledge of the frequency and clinical significance of PPVA is important for the care of patients with cirrhosis.

Keywords: Portal hypertension, TIPS, Hypoxia, Cirrhosis, Balloon-occluded Retrograde Transvenous Obliteration (BRTO)

\section{Introduction}

Portal hypertension is a common complication of cirrhosis. The increased pressure in the portal system leads to the development of portosystemic collateral vessels. Many pathways of collateral communication between the portal and systemic circulation have been described [1,2]. Some cirrhotic patients with portal hypertension develop collateral communication between the portal system and the pulmonary veins $[3,4]$. These collaterals have been called Portopulmonary Venous Anastomosis (PPVA). The term PPVA differentiates direct portal to pulmonary vein anastomosis from the intra-pulmonary shunts associated with the Hepatopulmonary Syndrome (HPS). This report describes a cirrhotic patient diagnosed with HPS. He was not a candidate for liver transplantation. In the setting of progressive symptoms of defective oxygenation, further studies were done to find an additional treatable cause of hypoxemia. Computed tomography revealed a PPVA connecting a large paraesophageal varices to the right inferior pulmonary vein. We hypothesized that the shunt may be contributing to the hypoxemia. We also hypothesized that the hypoxia might be improved if the portal pressure was reduced or if the PPVA was obliterated. There is limited data in the literature about the relation between PPVA and clinically significant hypoxia.

\section{Case Report}

The patient was a 52 year old male incarcerated in the state prison system. In August, 2012, he was admitted to a large referral prison hospital for minor trauma. Close questioning revealed episodes of dizziness and near syncope while standing. He had a past medical history of HCV associated cirrhosis (MELD score 13), systemic arterial hypertension, and hyperlipidemia. He also had a history of mild Portosystemic Encephalopathy (PSE) and nonbleeding gastric and esophageal varices. Physical examination showed cutaneous spider angiomata, central cyanosis, and bilateral symmetric upper extremity digital clubbing. Laboratory values showed hemoglobin of $14.1 \mathrm{~g} / \mathrm{dL}$, platelets of $38,000 / \mathrm{mm}^{3}$, and leukocyte count $3,800 / \mathrm{mm}^{3}$. During the hospitalization the patient was noted to have abnormal peripheral pulse oximetry on room air: supine $83 \%$; standing $75 \%$. The oximetry corrected to $95 \%$ when he breathed $40 \%$ oxygen by face mask. Arterial 
blood gases on room air showed $\mathrm{pH} 7.44, \mathrm{pCO}_{2} 28 \mathrm{mmHg}, \mathrm{pO}_{2} 72$ $\mathrm{mmHg}$, and $\mathrm{HCO}_{3} 19 \mathrm{mEq} / \mathrm{dL}$. The chest radiograph was normal. Computed Tomography (CT) of the chest with intravenous contrast showed portosystemic collaterals and no findings suggestive of large or numerous intraparenchymal pulmonary arteriovenous shunts. A PPVA was not reported. Spirometry and diffusing capacity for carbon dioxide were normal. The alveolar arterial gradient was $82 \mathrm{mmHg}$ on room air (normal for age is less than 17). With the patient on $100 \%$ oxygen, the $\mathrm{PaO}_{2}$ was $421 \mathrm{mmHg}$, with a calculated shunt fraction of $19.3 \%$ (normal $<5 \%$ ). A contrast enhanced echocardiogram was obtained. Agitated saline was injected via the right antecubital vein. Bubbles were first seen in the right atrium and then appeared in the left atrium after three heartbeats. The whole clinical picture (cirrhosis, hypoxemia, orthodeoxia, platypnea, and positive contrast echocardiogram) supported the diagnosis of HPS. The patient was discharged on continuous oxygen by nasal cannula at two liters per minute.

Seven months later he was admitted for PSE precipitated by methicillin sensitive staphylococcus bacteremia. During recovery from the PSE, the patient complained of worsening hypoxemia and related symptoms. He had several episodes of near syncope when he took a shower without oxygen. He required $40 \% \mathrm{FiO}_{2}$ to prevent exertional dyspnea. A series of investigations were performed to find possible causes of hypoxemia in addition to HPS. A ventilation perfusion lung scan showed a low probability for pulmonary embolism. A right heart catheterization showed normal right sided pressures (RA mean pressure $6 \mathrm{mmHg}, \mathrm{RV}$ pressure 22/1, PA 22/11, mean PA pressure 40, PCWP 10). An intra-cardiac echocardiogram showed no evidence of a PFO. Contrast enhanced echocardiography was repeated and confirmed HPS. Bubbles were first seen in the right atrium and then appeared in the left atrium after four heartbeats.

A thoracic high resolution CT angiogram with pulmonary embolism protocol was performed to look for a large intrapulmonary arteriovenous malformation amenable to embolization. No intrapulmonary shunt was visualized. However, the CT demonstrated a collateral venous connection between a paraesophageal varices and the right inferior pulmonary vein. A non enhancing low density area was noted within the contrast filled right inferior pulmonary vein and the left atrium. This "filling defect" was the pseudothrombus formed from the mixing of non contrast blood from the PPVA with the contrast in the left atrium (Figure 1) [5]. On review of his prior CT scan, the PPVA had been present, but was missed (Figure 2).

Because he was incarcerated, he was not a candidate for liver transplant, the standard treatment for HPS. We hypothesized that the PPVA may be contributing to his hypoxemia, along with the HPS. Various therapeutic options were discussed with consulting services and the patient. Catheter based transportal shunt obliteration was considered, but the risk of systemic embolization appeared considerable. The patient was counseled about the risks and benefits of a Transjugular Intrahepatic Portosystemic Shunt (TIPS), a reported treatment for HPS and a possible way to reduce flow through the PPVA. TIPS was performed. Portal pressure was initially found to be $14 \mathrm{mmHg}$. After the procedure, portal pressure dropped to $9 \mathrm{mmHg}$ with a central venous pressure of $6 \mathrm{mmHg}$ and a final portosystemic gradient of $3 \mathrm{mmHg}$. After creation of TIPS, contrast was injected into the coronary (left gastric) vein and no significant shunting to the pulmonary vein was noted. There were no significant complications.

The following benefits in our patient's clinical course were noted after TIPS: improved sense of well-being; oxygen requirements decreased; ability to perform all tasks with $2 \mathrm{~L} /$ min oxygen by nasal cannula; oxygen saturation remaining in the low 90 s. He also had no signs of portosystemic encephalopathy after the procedure.

Over the next two months the patient experienced worsening pulmonary symptoms and progressive decrease in sense of wellbeing. After informed consent, the patient was readmitted for catheter based obliteration of the PPVA. On the day of admission, he was complaining of dyspnea. His oxygen saturation was $85 \%$ on room air. The procedure was performed under general anesthesia. In conjunction with cardiologists, interventional radiology obtained venous access in both femoral veins and right internal jugular vein. The internal jugular vein was used by the radiologist to perform contrast injection and deployment of the plugs and coils.

Both femoral veins were used by the electrophysiology cardiologist. The right femoral vein was used to insert the transseptal needle to gain access to the left atrium. The left femoral vein was used to insert the intra-cardiac ultrasound probe. This intra-cardiac echo was used to assess the anatomy of the inter-atrial septum. The left femoral vein was also used for the

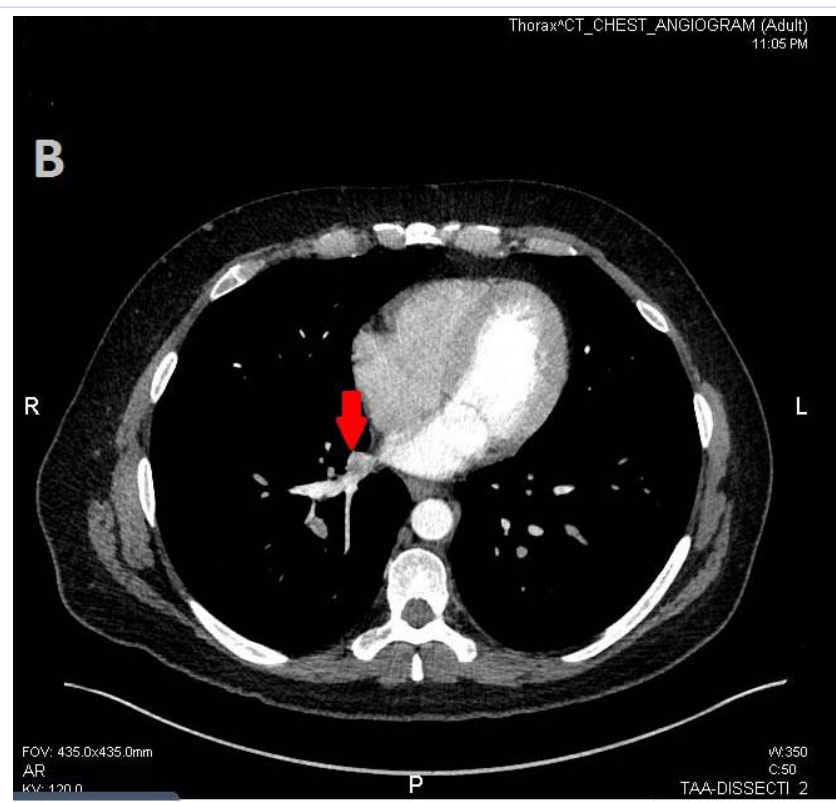

Figure 1: Axial image of CT thorax, showing the PPV as a "filling defect" in delayed venous phase. 


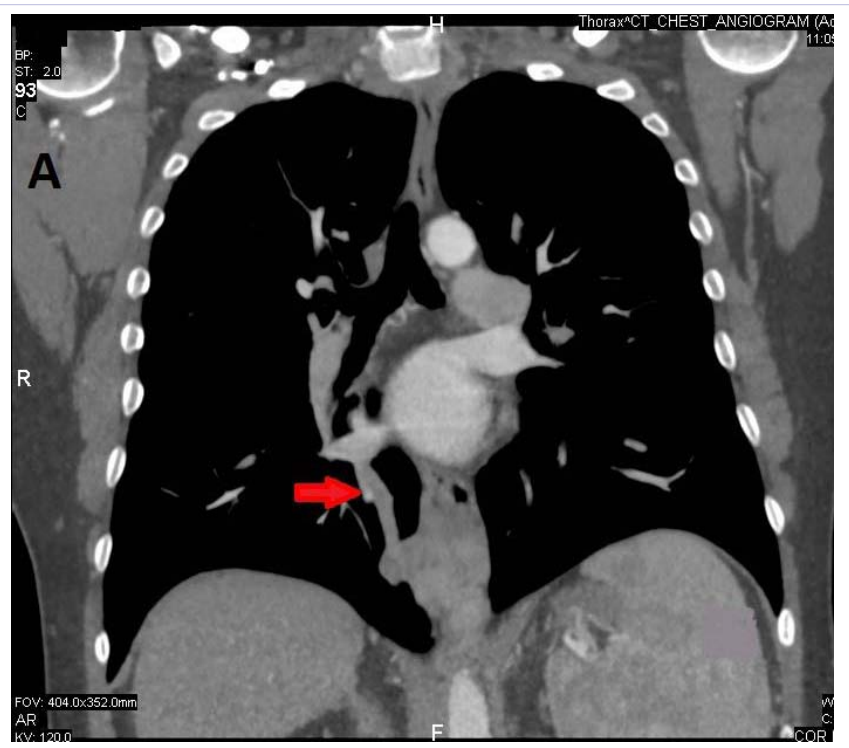

Figure 2: Coronal section view of CT thorax showing PPVA.

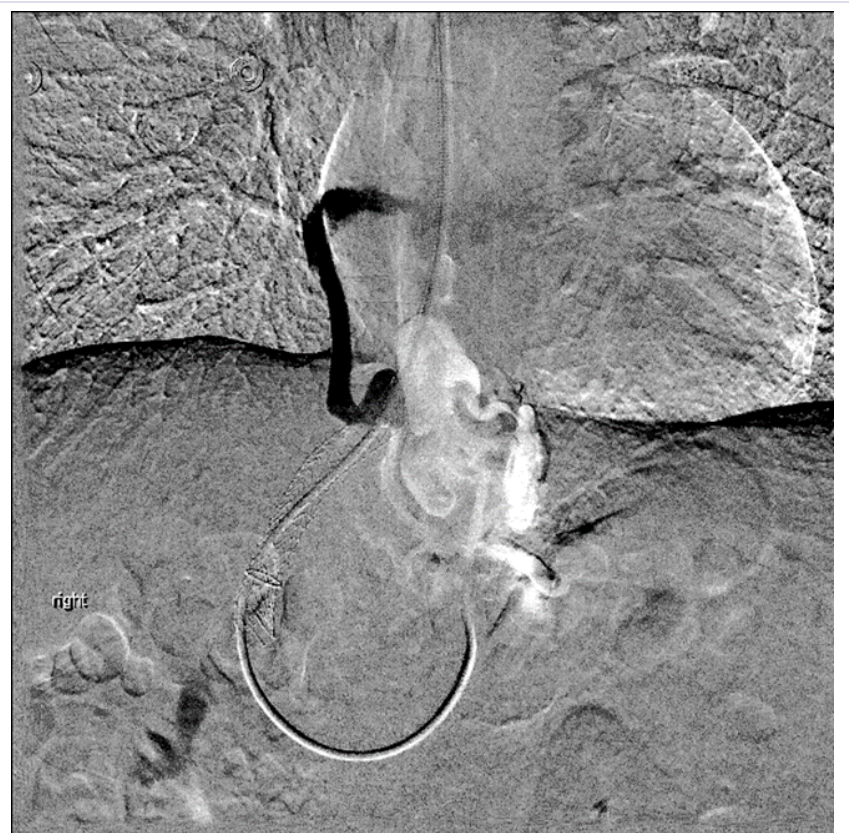

Figure 3: Injection of coronary vein using the internal jugular access through the TIPS showing PPVA.

electrophysiology catheter which could record and pace in the event of an abnormal cardiac rhythm.

Injections of the coronary vein using the internal jugular access while passing through the TIPS were performed to visualize the PPVA (Figure 3). Trans-septal puncture was performed using fluoroscopic and intracardiac echo guidance to obtain trans-septal access from right atrium into left atrium (LA) which was confirmed by LA pressure of $18 \mathrm{mmHg}$. The right inferior pulmonary vein was cannulated and access into the PPVA was achieved. The trans-septal sheath was used to place a long 6 French guiding cannula into the PPVA that measured $6 \mathrm{~mm}$ in diameter. Through this sheath, three 8mm Amplatzer plug devices were used to embolize the anastomosis. This was augmented by several $10 \mathrm{~mm}$ Nestor coils through a long Berenstein 5 French catheter. At the conclusion of the procedure, the PPVA was completely occluded (Figure 4).

There were no complications from the procedure. However, the patient remained hypoxic, requiring oxygen supplementation continuously since the procedure.

\section{Literature Review}

PubMed was used to search the medical literature using "portopulmonary venous anastomosis" as the search terms (with and without a hyphen or space). Fourteen articles were identified. An article was considered relevant if it described one or more patients with PPVA as defined above. Eleven out of 14 articles were relevant. Articles were read and the references in the articles were searched and new articles were retrieved and read. Searching and reading references were repeated until no new articles were retrieved. In total, 15 relevant articles describing 43 patients with PPVA were retrieved. The articles provided useful information regarding three major questions raised by our case.

Among patients with advanced cirrhosis, what is the frequency of PPVA?

Eight articles [3,6-12] were relevant to this "frequency" question. Each of these articles describes a series of subjects with cirrhosis who were investigated with a technique capable of proving the presence or absence of a PPVA (Table 1).

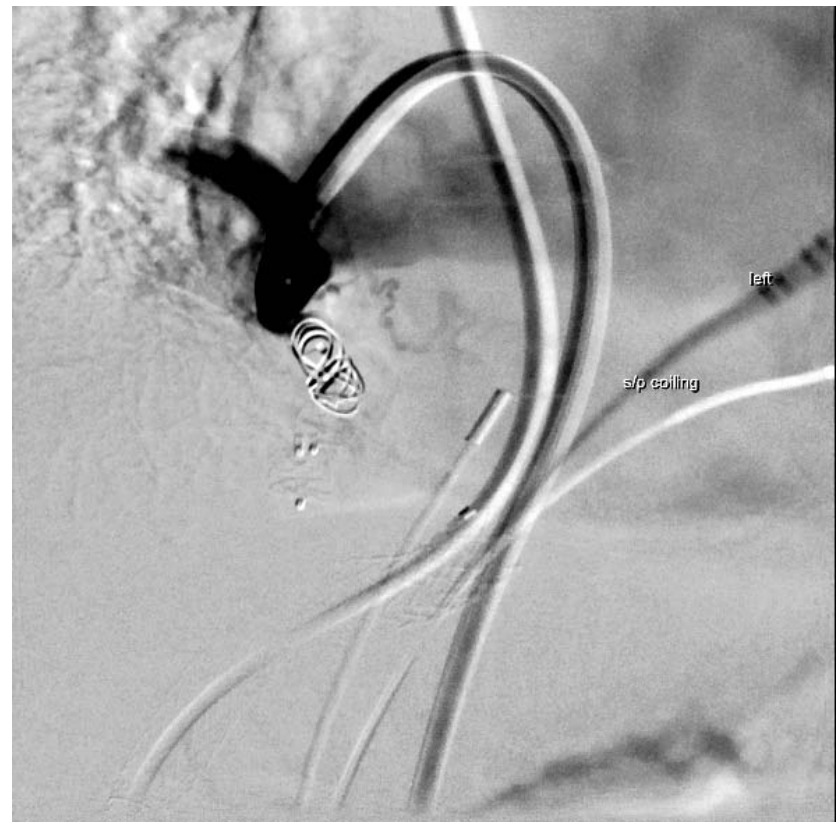

Figure 4: Injection of contrast through the femoral access showing total occlusion of PPVA post coiling. 
Three studies from the 1950s used post-mortem injection portography to investigate the venous anatomy of cirrhosis $[6,7,11]$. Six out of $51(12 \%)$ cadavers with cirrhosis showed a PPVA.

In 1961 investigators used intrasplenic injection of radioactive krypton 85 to identify a PPVA in 1 of 12 (8\%) subjects with cirrhosis [12]. Solubilized radioactive krypton gas is removed from the blood during one pass through the lungs. An injection of krypton 85 into the spleen (portal vein) is usually associated with no rise in arterial krypton, unless there are intrapulmonary shunts (HPS) or PPVA. The investigators injected krypton 85 into the spleen of 12 patients with cirrhosis. Because of krypton's removal by the pulmonary alveolar-capillary interface, most subjects had trivial amounts of krypton in blood drawn from the radial artery. One patient had a very large post-injection arterial concentration of krypton. In this patient, injection of krypton into a peripheral vein was not associated with an increased arterial krypton, thus ruling out intracardiac and intrapulmonary shunts.

Two studies in the 1980s, described subjects with portal hypertension who were studied with transhepatic portography $[9,10]$. Collectively, these very similar studies demonstrated a PPVA in 11 out of 53 (21\%) subjects. A subset of 15 subjects underwent imaging by both transhepatic portogram and a contrast enhanced (bubble) echocardiogram [10]. PPVA was demonstrated in 5 subjects (33\%). Intracardiac and intrapulmonary shunts were ruled out by the absence of left atrial bubbles after bubble injection into the inferior vena cava. The similarity of the methods using radioactive krypton 85 and contrast enhanced (bubble) echocardiography is apparent.

Two studies used balloon occlusion retrograde transvenous venography in 40 subjects with cirrhosis $[3,8]$ to demonstrate PPVA in 7 subjects (18\%). In one study [8], a subset of subjects had imaging with both the balloon-occluded retrograde transvenous venography and contrast enhanced (bubble) echocardiography. PPVA was demonstrated in 6 out of $19(32 \%)$. This study suggests that contrast enhanced echocardiography is a more sensitive test for identifying PPVA than either transhepatic portography or balloon occlusion retrograde transvenous venography.

The literature review identified 7 articles [5,13-18] that presented a total of 10 case reports of PPVA found at autopsy or in routine clinical care. These isolated case reports have some relevance to the "frequency" question. They demonstrate the role of improved imaging technology, over time, in determining the frequency of PPVA. In the 40 years from 1956 until 1996, there

Table 1: Published case series relevant to the frequency of PPVA in portal hypertension.

\begin{tabular}{|c|c|c|c|c|c|}
\hline $\begin{array}{l}\text { Purpose of } \\
\text { Study }\end{array}$ & $\begin{array}{l}\text { Test Used to Identify } \\
\text { PPVA }\end{array}$ & $\begin{array}{l}\text { Number } \\
\text { Tested }\end{array}$ & $\begin{array}{l}\text { Number with } \\
\text { PPVA (\%) }\end{array}$ & Comments & References \\
\hline $\begin{array}{l}\text { Anatomic } \\
\text { study of } \\
\text { cirrhosis }\end{array}$ & Post-mortem portography & 7 & $1(14 \%)$ & No clinical details & $\begin{array}{l}\text { (Schoenmackers \& } \\
\text { Vieten, 1953) }[11]\end{array}$ \\
\hline $\begin{array}{l}\text { Anatomic } \\
\text { study of } \\
\text { cirrhosis }\end{array}$ & Post-mortem portography & 34 & $3(9 \%)$ & No clinical details & $\begin{array}{l}\text { (Doehner et al., } \\
\text { 1956) [7] }\end{array}$ \\
\hline $\begin{array}{l}\text { Anatomic } \\
\text { study of } \\
\text { cirrhosis }\end{array}$ & Post-mortem portography & 10 & $2(20 \%)$ & No clinical details & $\begin{array}{l}\text { (Calabresi \& } \\
\text { Abelmann, 1957) [6] }\end{array}$ \\
\hline $\begin{array}{l}\text { Frequency } \\
\text { of PPVA in } \\
\text { cirrhosis }\end{array}$ & Splenic injection of Kr85 & 12 & $1(8 \%)$ & $\begin{array}{l}\text { No correlation of } \mathrm{O}_{2} \text { saturation with } \\
\text { PPVA }\end{array}$ & $\begin{array}{l}\text { (Shaldon et al., 1961) } \\
{[12]}\end{array}$ \\
\hline $\begin{array}{l}\text { Ability of } \\
\text { method to } \\
\text { show PPVA }\end{array}$ & Transhepatic portography & 22 & $4(18 \%)$ & No clinical details & (Sano et al., 1982) [9] \\
\hline $\begin{array}{l}\text { Ability of } \\
\text { method to } \\
\text { show PPVA }\end{array}$ & $\begin{array}{c}\text { Transhepatic portography } \\
\text { alone }\end{array}$ & 31 & $7(23 \%)$ & Same series as below & $\begin{array}{l}\text { (Sano et al., 1984) } \\
{[10]}\end{array}$ \\
\hline $\begin{array}{l}\text { Ability of } \\
\text { method to } \\
\text { show PPVA }\end{array}$ & $\begin{array}{c}\text { Transhepatic } \\
\text { portography plus bubble } \\
\text { echocardiography }\end{array}$ & 15 & $5(33 \%)$ & Same series as above & $\begin{array}{l}\text { (Sano et al., 1984) } \\
{[10]}\end{array}$ \\
\hline $\begin{array}{l}\text { Ability of } \\
\text { method to } \\
\text { show PPVA }\end{array}$ & $\begin{array}{l}\text { Balloon-occluded } \\
\text { retrograde transvenous } \\
\text { venography }\end{array}$ & 21 & $3(14 \%)$ & For control of variceal hemorrhage & $\begin{array}{l}\text { (Miura et al., 2013) } \\
\text { [3] }\end{array}$ \\
\hline $\begin{array}{l}\text { Ability of } \\
\text { method to } \\
\text { show PPVA }\end{array}$ & $\begin{array}{l}\text { Balloon-occluded } \\
\text { retrograde transvenous } \\
\text { venography alone }\end{array}$ & 19 & $4(21 \%)$ & For control of variceal hemorrhage & $\begin{array}{l}\text { (Kariya et al., 2014) } \\
{[8]}\end{array}$ \\
\hline $\begin{array}{l}\text { Ability of } \\
\text { method to } \\
\text { show PPVA }\end{array}$ & $\begin{array}{l}\text { Balloon-occluded } \\
\text { retrograde transvenous } \\
\text { venography plus bubble } \\
\text { echocardiography }\end{array}$ & 19 & $6(32 \%)$ & For control of variceal hemorrhage & $\begin{array}{l}\text { (Kariya et al., 2014) } \\
{[8]}\end{array}$ \\
\hline
\end{tabular}


were only two case reports of PPVA discovered at autopsy or in routine clinical care $[13,18]$. But in the last 16 years, there have been eight case reports in five articles [5,14-17]. The increasing number is due to the use of advanced high resolution computed tomography and magnetic resonance imaging in routine clinical care.

Some of the eight case series in the Table have relevance to the "significance" question. The study of Shaldon et al. [12] was performed to see if PPVA could explain the varying degree of finger clubbing and hypoxia seen in 12 patients with cirrhosis. They demonstrated the presence of a PPVA shunt in one out of the 12 patients. But the authors could not correlate the positive result (presence of PPVA in one patient) with the severity of finger clubbing or hypoxia in the 12 patients. That is, the single patient with a very large PPVA had an oxygen saturation of $96 \%$. But cirrhotic patients with severe hypoxia and finger clubbing had no PPVA. The authors gives the following argument to make the case that PPVA could not cause significant hypoxia. Given that portal venous oxygen saturation would never be lower than $75 \%, 20 \%$ of the cardiac output would have to pass through the PPVA to reduce the arterial oxygen saturation to $95 \%$. The total splanchnic inflow rarely exceeds $25 \%$ of the cardiac output. For the PPVA to cause hypoxia, almost the entire portal flow would have to go through the shunt. They conclude that PPVA does not cause clinically significant hypoxia.

Four case series in the Table $[3,8-10]$ were prompted by reports of systemic embolization associated with needle or catheter techniques used to treat or prevent bleeding from gastroesophageal varices [19]. The authors hypothesized that occult PPVA could increase the risk of systemic embolization as a complication of treating gastroesophageal varices with sclerosing thrombosing, or occluding materials. Miura et al. [3] reviewed evidence for systemic embolization associated with endoscopic sclerotherapy for gastroesophageal varices with cyanoacrylate and percutaneous transhepatic obliteration of gastroesophageal varices with gel foam. Ellman et al. [19] reported two cases in which particles of gel foam used to embolize the coronary and short gastric veins passed into the systemic arterial circulation, presumably through a PPVA. Embolization to the brain, spleen and heart occurred.

These case reports ( 7 articles, 10 cases of PPVA) gives an incomplete information regarding the clinical significance of PPVA [4,13-18]. The oldest case report (1956) was an autopsy finding on a patient with cirrhosis who had a PPVA demonstrated by postmortem angiogram [13]. Although the patient had severe cardiopulmonary disease complicating cirrhosis, there is no convincing evidence that the PPVA was clinically significant. The next case report was from an interventional radiology group who encountered a patient with a PPVA during their routine clinical use of transhepatic portography for the care of patients with cirrhosis [18]. The PPVA was without an apparent clinical significance. In each of the remaining eight case reports the PPVA was an incidental finding discovered while rendering care for individual cirrhotic patients [5,14-17]. In two case reports
$[14,17]$ the authors believed that the PPVA caused significant cardiac and pulmonary disease. In our opinion, the clinical details given by the authors cannot conclusively relate the patients' clinical conditions with the presence of the PPVA. There is no convincing published evidence that, PPVA is associated with clinically significant hypoxia.

We were not able to find any published experience of obliteration of a PPVA in an attempt to improve oxygenation in a patient with cirrhosis. Most reported patients with PPVA have been asymptomatic. The published literature does not support an association of PPVA with hypoxia. Our patient had minimal symptoms when first seen. However, he fulfilled the criteria for HPS [20]: liver disease (cirrhosis with portal hypertension), an oxygenation defect (room air partial pressure of oxygen less than $80 \mathrm{mmHg}$ ), and positive findings on contrast enhanced (bubble) echocardiography (contrast appearing in the left atrium after three heartbeats).

Physicians taking care of cirrhotic patients with hypoxia are supposed to look for a treatable cause. In the review of HPS by Rodríguez-Roisin et al. [20] the authors list, multiple reversible causes of hypoxemia that may coexist with HPS. They recommend that patients with moderately severe HPS (alveolar arterial oxygen gradient $\geq 15 \mathrm{~mm} \mathrm{Hg}$ and arterial oxygen levels less than $80 \mathrm{~mm} \mathrm{Hg}$ ) should be studied with HRCT with proper imaging sequencing [20]. Such a scan can identify pulmonary emboli and other pulmonary vascular disease. In addition, the CT scan may identify one or more very large intrapulmonary arteriovenous shunts that could be eradicated by catheter based obliteration [21]. If a PPVA is found, the "obliteration" question is bound to come up.

We believe that an increasing number of patients with HPS will be found with an incidental PPVA in the process of getting a HRCT for evaluation of hypoxia caused by any of the above conditions. The frequency of finding a PPVA with HRCT will depend on the sequences for imaging after the contrast bolus: 30 seconds for the pulmonary arterial phase, 60 seconds for the portal phase, and 120 seconds for equilibrium phase [3]. Our patient's PPVA was visualized on the 60 second portal phase (Figures 1 and 2). The frequency will also depend on the radiologist's knowledge of and suspicion for, PPVA. The PPVA was missed on our patient's first HRCT.

The pathway that led to the discovery of our patient's PPVA is likely to be repeated in the routine care of chronic liver disease patients. Patients with cirrhosis develop hypoxia that is investigated with HRCT that may demonstrate a PPVA. It is likely that other clinicians will ask the "obliteration" question. For our patient the procedure appeared to achieve the anatomic goal: obliteration. But it did not improve oxygenation. It is unlikely that we will treat hypoxia with PPVA obliteration in the future.

\section{Discussion}

PPVA as a consequence of portal hypertension was first reported by Schoenmackers \& Vieten [11] in 1953. The development of advanced body imaging, especially HRCT, has 
led to increasing numbers of case reports [3-5]. Based on our interpretation of the literature review, the frequency of PPVA in a patient with advanced cirrhosis, with known varices, is likely between $20 \%$ and $30 \%$. The frequency of finding a PPVA is dependent on the chosen technique: transhepatic portal venography or balloon occluded retrograde transvenous portal venography - 20\%; portal venography plus contrast enhanced echocardiography - 30\%; HRCT with proper timing of imaging - unknown. Even though many patients with advanced cirrhosis have had a HRCT, there has not been a large published case series that has reported the frequency of finding PPVA in that risk group using HRCT.

But what is the evidence that PPVA, if found, ever causes clinically significant hypoxia? The previously published case series and case reports provide no solid evidence that PPVA causes hypoxia. Time and experience has supported Shaldon's [12] theoretical case against PPVA causing hypoxia. Their final opinion was that a PPVA in a patient with cirrhosis and portal hypertension does not cause hypoxia, cyanosis, or clubbing. We concur. We do not recommend preforming CT scans routinely in hypoxic cirrhotics to look specifically for PPVA.

Our patient had HPS. TIPS has been used to successfully treat hypoxemia associated with severe HPS [22-28]. Failure of TIPS to improve oxygenation in HPS has also been reported $[29,30]$. The cause of the beneficial effect of the TIPS is likely multifactorial. TIPS has been used and recommended as a bridge to Orthotopic Liver Transplantation (OLT), the gold standard treatment for HPS. Because of the failure of TIPS to effectively treat our patient's HPS, we proceeded with catheter based obliteration of the PPVA. This was performed without complication. However, there was no convincing evidence of improvement in arterial oxygen saturation or pulmonary symptoms.

In conclusion, we believe that PPVA is common in cirrhotic patients with portal hypertension. The frequency of PPVA identification in such patients depends on the frequency of properly performed portal venography and HRCT scanning. If such investigations unexpectedly reveal a PPVA during the routine care of a patient with portal hypertension, it is likely that the PPVA has no clinical significance. If the patient has hypoxia, then HPS or some other cardiopulmonary disease is more likely the cause of hypoxia than the PPVA. The main clinical significance of PPVA is the risk it poses for systemic emboli if needle or catheter based techniques are used to treat or prevent bleeding from gastro-esophageal varices. Obliteration of the PPVA is likely to be important in that circumstance. In other circumstances, as in our patient, obliteration may not be justified.

\section{References}

1. Gallego C, Velasco M, Marcuello P, Tejedor D, De Campo L, Friera A Congenital and acquired anomalies of the portal venous system. Radiographics. 2002; 22(1): 141-159.

2. Kiyosue H, Mori H, Matsumoto S, Yamada Y, Hori Y, Okino Y. Transcatheter obliteration of gastric varices. Part 1. Anatomic classification. Radiographics. 2003; 23(4): 911-920.
3. Miura H, Yamagami T, Tanaka O, Yoshimatsu R. Portopulmonary venous anastomosis detected at balloon-occluded retrograde transvenous obliteration for gastric varices. J Vasc Interv Radiol. 2013; 24(1): 131-134. doi: 10.1016/j.jvir.2012.09.013

4. Yamagami T, Yoshimatsu R, Miura H, Yamada K, Minami M. Successful balloon-occluded retrograde transvenous obliteration of gastric varix via pericardiacophrenic vein after embolization of portopulmonary venous anastomosis. J Vasc Interv Radiol. 2013; 24(1): 137-139. doi: 10.1016/j.jvir.2012.09.014

5. Ko JM, Ahn MI, Han DH, Jung JI, Park SH. Dynamic CT and MRA findings of a case of portopulmonary venous anastomosis (PPVA) in a patient with portal hypertension: a case report and review of the literature. Acta Radiol. 2011; 52(5): 566-569. doi: 10.1258/ar.2011.100441

6. Calabresi P, Abelmann WH. Porto-caval and porto-pulmonary anastomoses in Laennec's cirrhosis and in heart failure. J Clin Invest. 1957; 36(8): 1257-1265.

7. Doehner GA, Ruzicka FF, Rousselot LM, Hoffman G. The portal venous system: on its pathological roentgen anatomy. Radiology. 1956; 66(2): 206-217.

8. Kariya S, Komemushi A, Nakatani M, Yoshida R, Kono Y, Shiraishi $\mathrm{T}$, et al. Portopulmonary venous anastomosis in balloon-occluded retrograde transvenous obliteration for the treatment of gastric varices. J Gastroenterol Hepatol. 2014; 29(7): 1522-1527. doi: 10.1111/jgh.12583.

9. Sano A, Kuroda Y, Moriyasu F, Takahashi Y, Koizumi S, Kimura S, et al. Porto-pulmonary venous anastomosis in portal hypertension demonstrated by percutaneous transhepatic cine-portography. Radiology. 1982; 144(3): 479-484.

10. Sano A, Nishizawa S, Sasai K, Imanaka K, Tanaka K, Hashimura T, et al. Contrast echocardiography in detection of portopulmonary venous anastomosis. AJR Am J Roentgenol. 1984; 142(1): 137-140.

11.Schoenmackers J, Vieten H. [Portocaval and portopulmonary anastomoses in postmortem portography]. Fortschr Geb Rontgenstr. 1953; 79(4): 488-498.

12. Shaldon S, Caesar J, Chiandussi L, Williams HS, Sheville E, Sherlock S. The demonstration of portapulmonary anastomoses in portal cirrhosis with the use of radioactive krypton (Kr85). N Engl J Med. 1961; 265: 410-414.

13. Blackburn CR. Acquired portal-pulmonary venous anastomosis complicating partial oesophago-gastrectomy in a patient with portal hypertension. Thorax. 1956; 11(1): 30-35.

14. Hast J, Kauczor HU, Heussel CP, Kreitner KF. [Spontaneous portopulmonary shunt with pulmonary infiltrates in liver cirrhosis: their CT and MRI imaging]. Rofo. 1999; 171(2): 172-174.

15. Kumar A, Gonzalez G, Wilkinson L, Mohammed TL, Castro-Pavia F, Glockner J, et al. Computed tomography findings of spontaneous porto-pulmonary shunts in 3 patients with portal hypertension. J Thorac Imaging. 2010; 25(3): W70-W74. doi: 10.1097/ RTI.0b013e3181a652fa.

16. Masi L, André A, Rémy-Jardin M, Rémy J. [Portal pulmonary venous anastomosis and portal hypertension]. J Radiol. 2002; 83(11):17691771.

17. Meyer RG, Orth T, Kreitner KF, Schirmacher P, Meyer zum Büschenfelde $\mathrm{KH}$, Gerken G. [Persistent pulmonary opacification as a sequela of portopulmonary shunt in portal vein thrombosis]. Z Gastroenterol. 1998; 36(11): 971-975. 
18. Nunez D, Russell E, Yrizarry J, Pereiras R, Viamonte M. Portosystemic communications studied by transhepatic portography. Radiology. 1978; $127(1): 75-79$.

19. Ellman BA, Curry TS, Glotzbach RE, Simpson PR. Systemic embolization as a complication of transhepatic venography. Radiology. 1981; 141(1), 67-71.

20. Rodríguez-Roisin R, Krowka MJ. Hepatopulmonary syndrome--a liverinduced lung vascular disorder. N Engl J Med. 2008; 358(22): 23782387. doi: 10.1056/NEJMra0707185.

21. Poterucha JJ, Krowka MJ, Dickson ER, Cortese DA, Stanson AW Krom RA. Failure of hepatopulmonary syndrome to resolve after liver transplantation and successful treatment with embolotherapy. Hepatology. 1995; 21(1): 96-100.

22. Allgaier HP, Haag K, Ochs A, Hauenstein KH, Jeserich M, Krause T, et al. Hepato-pulmonary syndrome: successful treatment by transjugular intrahepatic portosystemic stent-shunt (TIPS). J Hepatol. 1995; 23(1): 102.

23. Benítez C, Arrese M, Jorquera J, Godoy I, Contreras A, Loyola S, et al Successful treatment of severe hepatopulmonary syndrome with a sequential use of TIPS placement and liver transplantation. Ann Hepatol. 2009; 8(1): 71-74.

24. Chevallier P, Novelli L, Motamedi JP, Hastier P, Brunner P, Bruneton JN Hepatopulmonary syndrome successfully treated with transjugular intrahepatic portosystemic shunt: a three-year follow-up. J Vasc Interv Radiol. 2004; 15(6): 647-648.
25. Lasch HM, Fried MW, Zacks SL, Odell P, Johnson MW, Gerber DA, et al. Use of transjugular intrahepatic portosystemic shunt as a bridge to liver transplantation in a patient with severe hepatopulmonary syndrome. Liver Transpl. 2008; 7(2): 147-149.

26. Paramesh AS, Husain SZ, Shneider B, Guller J, Tokat I, Gondolesi GE, et al. Improvement of hepatopulmonary syndrome after transjugular intrahepatic portasystemic shunting: case report and review of literature. Pediatr Transplant. 2003; 7(2): 157-162.

27. Riegler JL, Lang KA, Johnson SP, Westerman JH. Transjugular intrahepatic portosystemic shunt improves oxygenation in hepatopulmonary syndrome. Gastroenterology. 1995; 109(3): 978983.

28. Selim KM, Akriviadis EA, Zuckerman E, Chen D, Reynolds TB. Transjugular intrahepatic portosystemic shunt: a successful treatment for hepatopulmonary syndrome. Am J Gastroenterol. 1998; 93(3): 455-458.

29. Corley DA, Scharschmidt B, Bass N, Somberg K, Gold W. Lack of efficacy of TIPS for hepatopulmonary syndrome. Gastroenterology. 1997; 113(2): 728-730

30. Martinez-Palli G, Drake BB, Garcia-Pagan JC, Barbera JA, Arguedas MR, Rodriguez-Roisin R, et al. Effect of transjugular intrahepatic portosystemic shunt on pulmonary gas exchange in patients with portal hypertension and hepatopulmonary syndrome. World J Gastroenterol. 2005; 11(43): 6858-6862. 